\title{
Globalization, Regional Productivity, Taste Bias and Internal Spatial Distribution
}

\author{
Dionysios Karavidas \\ Department of Economics, Christian-Albrechts-Universität zu Kiel, Kiel, Germany \\ Email: d.karavidas@economics.uni-kiel.de
}

How to cite this paper: Karavidas, D. (2018) Globalization, Regional Productivity, Taste Bias and Internal Spatial Distribution. Theoretical Economics Letters, 8, 626-648. https://doi.org/10.4236/tel.2018.83043

Received: January 12, 2018

Accepted: February 23, 2018

Published: February 26, 2018

Copyright $\odot 2018$ by author and Scientific Research Publishing Inc. This work is licensed under the Creative Commons Attribution International License (CC BY 4.0).

http://creativecommons.org/licenses/by/4.0/

(c) (i) Open Access

\begin{abstract}
I consider an integrated model consisting of a system of two symmetric regions and the rest of the world that features 1) globalization, 2) regional heterogeneity in productivity, and 3) taste bias over domestic and foreign goods as key determinants of spatial agglomeration. I show that falling external trade barriers favor internal agglomeration. Moreover, a reduction in relative productivity compensates for the trade barriers between the two symmetric regions and the rest of the world; this also favors internal agglomeration of the mobile factor. In addition, I consider two cases of taste bias namely ethnocentrism and xenocentrism. I find that a shift of consumer preferences in the two symmetric regions with respect to goods that are made in the rest of the world results in internal agglomeration, too. Finally, a shift of consumer preferences in a region with respect to goods that are made in the other region results 1) in internal agglomeration under ethnocentrism, and 2) in internal dispersion under xenocentrism.
\end{abstract}

\section{Keywords}

Globalization, Regional Productivity, Consumer Taste Bias, Internal Geography

\section{Introduction}

New Economic Geography has provided various explanations for the agglomeration or dispersion of economic activities over a geographical space. ${ }^{1}$ The present paper contributes to the literature by studying an integrated model that features 1) globalization, 2) regional heterogeneity in productivity, and 3) taste bias over domestic and foreign goods as key determinants of spatial agglomeration. These three factors have been reported, both empirically and theoretically, to influence the spatial distribution of economic activities and hence I believe that it is im-

${ }^{1}$ The interested reader should consult Fuj04 [1] for an introduction to the topic. 
perative to study their interactions in a model that combines them all.

Concerning globalization, several indicators illustrate that economies are becoming more integrated over the years. For instance, the value of trade as a percentage of the world GDP rose from 42\% in 1980 to $60 \%$ in 2013 (Source: World Bank) and FDI increased from $6.5 \%$ of the world GDP in 1980 to $31 \%$ in 2006 (Source: IMF). The increased level of integration is mainly due to institutional changes within countries and various trade agreements among countries which led to the abandonment of many trade barriers. Globalization has indeed affected the spatial concentration of economic activities within countries or regions in various ways and hence this relationship has become a major research issue for trade economists. Monfort and Nicolini [2] study the impact of international economic integration on the agglomeration process with the use of a model with two symmetric countries, each consisting of two regions. They show that a reduction in interregional and/or international trade costs favors regional agglomeration of economic activities. In the same line of research, Monfort and van Ypersele [3] study how a country's spatial distribution affects the agglomeration forces in its partner country. In contrast to the work of Monfort and Nicolini [2], they assume that interregional transaction costs are not identical in the two countries. They exhibit that both integration and agglomeration in one country make agglomeration in the partner country less likely. Krugman and Livas-Elizondo [4] show that openness to international trade leads to internal dispersion of economic activities when rent and commuting costs are present. Brülhart et al. [5] study the impact of improved external market access on the internal geography of a trading bloc consisting of two symmetric regions. Without providing analytical expressions for market's centrifugal and centripetal forces, their work suggests that improved external market access results in internal agglomeration of the mobile factor.

The assumption that regions are heterogeneous with respect to their productivity is of high importance as many parts of the world, that recently became more integrated, have a higher productivity growth rate than the rest of the world. For instance, over the last twenty years, the Chinese average annual productivity growth rate was approximately $8.9 \%$ whereas that of the EU and the US was around $1.5 \%$. During the same period of time, India achieved an average productivity growth rate of $5.4 \%$ per year. This is greater than that of South Korea (approximately 3.9\%), which is, according to the data of World Bank, the country with the highest productivity growth rate among developed countries.

Moreover, due to the process of integration and the development of technology, there exist transmissions of ideas and values around the world. As a result, worldwide consumer preferences are updated and some groups of consumers develop a xenocentristic attitude as they put a higher value on foreign made products, styles or ideas rather than those of their own country (Johnson [6]). At the same time, other consumers develop an ethnocentristic attitude as they believe that buying foreign products is unpatriotic and can harm the domestic 
economy (Balabanis et al. [7]; Klein [8]). Ethnocentrism still exists in the EU although its people tend to be less ethnocentric than those in developing and emerging countries (Lindquist et al. [9]; Sharma et al. [10]).

The latest EU Enlargements have expanded the European borders to a set of countries in the East, which are characterized by lower development levels, and significant institutional and cultural differences. In the present work, I extend the framework of Brülhart et al. [5] counting for technological differences and biased preferences in order to further explore the impact of globalization on the internal distribution of a trading bloc's economic activity. More specifically, I ask how changes in relative importance between the trading bloc and Foreign market are likely to affect the internal spatial distribution of the trading bloc's economic activity. I explore this issue in a model with two countries, labeled Foreign country and Domestic country, which is a union of two regions. In this setup, technological differences concern the regional heterogeneity in labor productivity and biased preferences deal with the idiosyncrasies in the consumer taste.

The results in this paper complement very well several existing ones. First of all, my results confirm those of Brülhart et al. [5] by showing that falling external transportation costs favor internal agglomeration. They also clarify conceptually and analytically why this must be the case. I contribute to the existing literature by showing analytically how falling external economic barriers generate a number of spatial dynamics linked to better access to Foreign market and import competition (e.g. The EU Enlargement). Moreover, a decrease in relative productivity has an identical impact as the one that comes from falling external trade barriers. Intuitively, a reduction in relative productivity compensates the effect that comes from the trade barriers between Domestic country and Foreign country, and this favors internal agglomeration of the mobile factor. It should be noted that these results are derived under the quasi-linearity assumption, which means that the income effect has been eliminated. In order to study the robustness of the model, I relax this assumption (Section 2.5) by considering a Cobb-Douglas utility function. My findings exhibit that the model is fully robust, as falling external trade barriers result again in internal agglomeration of the economic activity.

Furthermore, I compare the distribution of the mobile factor between the market equilibrium allocation and the socially optimal allocation. My results show that the market level of internal agglomeration is higher than the socially preferred level for some values of the internal freeness of trade. For high and low values of the internal freeness of trade, both solutions coincide with respect to the distribution of the mobile factor. This result is in line with the literature, as Ottaviano and Thisse [11], Tabuschi and Thisse [12], Charlot et al. [13], Pflüger and Südekum [14] also conclude that the market equilibrium outcome differs from the social optimum with respect to the distribution of the mobile factor. My welfare analysis also enhances the existing literature in a key aspect. I calcu- 
late the threshold value of the internal freeness of trade that determines the efficiency of the market equilibrium outcome and I show how this value is affected by trade policies and technological interventions.

Finally, concerning the effects of taste bias, I show that a shift of consumer preferences in Domestic country with respect to goods that are made in Foreign country results in internal agglomeration because this behavior compensates for the trade barriers between Domestic country and Foreign country. In Domestic country, a shift of consumer preferences in a region with respect to goods that are made in its partner region results 1) in internal agglomeration in the case of ethnocentrism, and 2) in internal dispersion in the case of xenocentrism. The model also shows that in the case of ethnocentrism, internal agglomeration is favored for intermediate and high values of the internal freeness of trade, whereas in the case of xenocentrism, internal agglomeration takes place only for intermediate values of the internal freeness of trade.

The remainder of the paper is organized as follows. Section 2 presents the model and characterizes the location patterns of the market equilibrium under regional heterogeneity in labor productivity. It also studies the robustness of the results. Section 3 derives the socially optimal spatial pattern. Section 4 introduces taste bias across consumers and specifies the location patterns of the market equilibrium under consumer taste bias. Finally, Section 5 concludes and summarizes the main findings of the model.

\section{The Model}

\subsection{Set up}

Based on Brülhart et al. [5] the economy consists of two countries named Domestic and Foreign. Domestic country is a union of two regions labeled North and South, respectively. In each country there exist two types of household supplying unskilled and skilled labor. Both of them inelastically supply one-factor unit each. In Domestic country unskilled labor is immobile and equally distributed across regions. The total mass of unskilled labor in each region is $\rho$. Skilled labor is interregionally mobile. I normalize the total mass of skilled labor to one. A proportion $\lambda$ of skilled households is located in North and the rest $(1-\lambda)$ is located in South. In Foreign country there exist $\rho$ immobile unskilled households and $n$ immobile skilled households. Each household derives utility from an aggregate of manufacturing varieties and an agricultural good.

In each country there exist two production sectors called agricultural and manufacturing sector, respectively. The agricultural sector produces a homogeneous good in a perfectly competitive environment under constant returns with unskilled labor as input. There is no transport cost for the agricultural goods; the agricultural sector is sufficiently large to guarantee positive output; the agricultural good also serves as the numeraire.

In addition, there exists a Dixit-Stiglitz manufacturing sector that produces a large variety of differentiated products. Each variety is produced using both un- 
skilled and skilled labor. Unskilled labor is the variable input and skilled labor enters as fixed cost. Manufacturing goods are tradable with iceberg trade costs. The cost mark-up factor is denoted by $\tau_{u}>1$ for trade between the regions of Domestic country and by $\tau_{f}>\tau_{u}$ for trade of each region of Domestic country with Foreign country. Trade of manufacturing varieties within each region and within Foreign country is free.

Both countries are symmetric in terms of technology in the agricultural sector. However, the labor productivity differs across countries in the manufacturing sector with the one in Domestic country being higher than that in Foreign country. Without loss of generality, I normalize the labor productivity in Domestic country to be equal to one. In Foreign country the labor productivity is $0<\delta<1$. The production of a manufacturing variety in Domestic country requires one unit of unskilled labor as marginal cost and one unit of skilled labor as fixed cost. In Foreign country, a manufacturing variety is produced using $1 / \delta$ units of unskilled labor as marginal cost and one unit of skilled labor as fixed cost.

\subsection{Preferences and Demand}

Household preferences are characterized by a quasi-linear utility function with CES sub-utility over manufacturing varieties. In this kind of models, the quasi-linearity assumption is proposed by Pflüger [15] and also used in other works such as Pflüger and Südekum [14]. The quasi-linear preferences make the calculations simpler although do not take into account the income effect. Let the utility of a typical household located in region $i$ be

$$
U_{i}=\alpha \ln C_{X}^{i}+C_{A}^{i}
$$

with,

$$
C_{X}^{i}=\left(\int_{V} l_{i}(v)^{\frac{\sigma-1}{\sigma}} \mathrm{d} v\right)^{\frac{\sigma}{\sigma-1}}, \quad i=n, s, f
$$

where $0<\alpha<1$ and $\alpha<\kappa=\min \left\{R_{n}, R_{s}, R_{f}\right\} ; \sigma>1$ and $V=V_{n} \cup V_{s} \cup V_{f}$.

$C_{X}^{i}$ is the consumption of the manufacturing aggregate and $C_{A}^{i}$ denotes the consumption of the agricultural good. Per capita consumption of a household located in region $i$ is denoted by $l_{i}, V_{n}, V_{s}$ and $V_{f}$ are the numbers of varieties that are produced in North, South and Foreign country, respectively. $\sigma$ expresses the elasticity of substitution between any two manufacturing varieties. $\alpha$ is the expenditure on manufacturing products. $R_{n}, R_{s}$ and $R_{f}$ are the wages of skilled labor paid in North, South and Foreign country, respectively. The budget constraint of a representative household is given by

$$
P_{i} C_{X}^{i}+C_{A}^{i}=Y_{i}, \quad i=n, s, f .
$$

$Y_{i}$ denotes the household's income located in region $i . P_{n}$ is the perfect CES-price index for the manufacturing aggregate in North, 


$$
P_{n}=\left[\int_{V_{n}} p_{n}(v)^{1-\sigma} \mathrm{d} v+\int_{V_{s}}\left(\tau_{u} p_{s}(v)\right)^{1-\sigma} \mathrm{d} v+\int_{V_{f}}\left(\tau_{f} p_{f}(v)\right)^{1-\sigma} \mathrm{d} v\right]^{\frac{1}{1-\sigma}},
$$

and $P_{s}$ is the perfect CES-price index in South,

$$
P_{s}=\left[\int_{V_{s}} p_{s}(v)^{1-\sigma} \mathrm{d} v+\int_{V_{n}}\left(\tau_{u} p_{n}(v)\right)^{1-\sigma} \mathrm{d} v+\int_{V_{f}}\left(\tau_{f} p_{f}(v)\right)^{1-\sigma} \mathrm{d} v\right]^{\frac{1}{1-\sigma}} .
$$

Similarly, the CES-price index for Foreign country is

$$
P_{f}=\left[\int_{V_{n}}\left(\tau_{f} p_{n}(v)\right)^{1-\sigma} \mathrm{d} v+\int_{V_{s}}\left(\tau_{f} p_{s}(v)\right)^{1-\sigma} \mathrm{d} v+\int_{V_{f}} p_{f}(v)^{1-\sigma} \mathrm{d} v\right]^{\frac{1}{1-\sigma}}
$$

with $\tau_{f}>\tau_{u}>1$.

$p_{n}, p_{s}$, and $p_{f}$ denote the producer prices for a variety that is produced in North, South and Foreign country, respectively. Iceberg trade costs are formalized by the parameters $\tau_{u}$ and $\tau_{f}$. Iceberg trade cost implies that only $1 / \tau$ of a unit of a variety shipped arrives at its destination. It also implies that the consumer price of an imported variety is $p \tau$, where $p$ is the price of this variety at its region of origin.

Each household maximizes its utility subject to its budget constraint. It derives the demand functions for the manufacturing aggregate and the agricultural good as

$$
C_{X}^{i}=\frac{\alpha}{P_{i}}, \quad C_{A}^{i}=Y_{i}-\alpha, \quad i=n, s, f
$$

Moreover, the demand functions of a representative household located in North for manufacturing varieties are obtained as

$$
x_{n n}=\alpha p_{n}^{-\sigma} P_{n}^{\sigma-1}, x_{n s}=\alpha\left(\tau_{u} p_{s}\right)^{-\sigma} P_{n}^{\sigma-1}, x_{n f}=\alpha\left(\tau_{f} p_{f}\right)^{-\sigma} P_{n}^{\sigma-1} .
$$

$x_{n n}$ denotes the demand of a representative household located in North for varieties that are produced in North; $x_{n s}$ is the demand of the same household for varieties that are produced in South; $x_{n f}$ denotes the demand for varieties that are imported from Foreign country. Similarly, demand functions

$$
x_{s n}=\alpha\left(\tau_{u} p_{n}\right)^{-\sigma} P_{s}^{\sigma-1}, x_{s s}=\alpha p_{s}^{-\sigma} P_{s}^{\sigma-1}, x_{s f}=\alpha\left(\tau_{f} p_{f}\right)^{-\sigma} P_{s}^{\sigma-1}
$$

are obtained for a typical household located in South. $x_{s n}$ denotes the demand of a household located in South for varieties that are produced in North; $x_{s s}$ is the demand for varieties that are produced in South; $x_{s f}$ denotes the demand of the same household for varieties that are produced in Foreign country. Finally, the demand functions of a representative household located in Foreign country are

$$
x_{f n}=\alpha\left(\tau_{f} p_{n}\right)^{-\sigma} P_{f}^{\sigma-1}, x_{f s}=\alpha\left(\tau_{f} p_{s}\right)^{-\sigma} P_{f}^{\sigma-1}, x_{f f}=\alpha p_{f}^{-\sigma} P_{f}^{\sigma-1} .
$$

$x_{f n}$ is the demand of a typical household located in Foreign country for varieties that are produced in North; $x_{f s}$ denotes the demand of the same 
household for varieties that are produced in South; $x_{f f}$ is the demand for varieties that are produced in Foreign country.

The indirect utility is given by

$$
I_{i}=Y_{i}-\alpha \ln P_{i}, \quad i=n, s, f .
$$

\subsection{Production and Short-Run Market Equilibrium}

The agricultural good is produced in a perfectly competitive environment under constant returns with a unit input requirement of unskilled labor. Perfect competition enforces marginal cost pricing. Costless trade equalizes prices within Domestic country, and also between Domestic and Foreign country. This indirectly makes the wage rates of unskilled labor equal to one in both countries since the agricultural good serves as the numeraire.

Turning to the industrial sector, each manufacturing variety is supplied by a single firm. The market clearing condition for a variety requires that the total production is equal to the total demand for this variety. Thus, the market clearing condition for a variety that is produced in North is

$$
X_{n}=(\rho+\lambda) X_{n n}+(\rho+1-\lambda) \tau_{u} X_{s n}+(\rho+n) \tau_{f} X_{f n} .
$$

A part of the demand is caused by transport losses. Similarly, the market clearing condition for a variety that is produced in South is

$$
X_{s}=(\rho+\lambda) \tau_{u} x_{n s}+(\rho+1-\lambda) x_{s s}+(\rho+n) \tau_{f} X_{f s} .
$$

Also, the market clearing condition for a variety that is produced in Foreign country is

$$
X_{f}=(\rho+\lambda) \tau_{f} x_{n f}+(\rho+1-\lambda) \tau_{f} x_{s f}+(\rho+n) x_{f f} .
$$

I assume that all firms within a region have access to the same technology. Moreover, the labor productivity in Domestic country is higher than that in Foreign country. Thus, the profits of a representative firm located either in North or in South are

$$
\pi_{i}=\left(p_{i}-1\right) X_{i}-R_{i}, \quad i=n, s .
$$

Similarly, the profits of a representative firm located in Foreign country are

$$
\pi_{f}=\left(p_{f}-\frac{1}{\delta}\right) X_{f}-R_{f} .
$$

Imposing the Chamberlinian large group assumption, each producer perceives an elasticity of demand equal to $\sigma$. Thus, profit-maximizing prices are constant mark-ups over marginal costs. Then,

$$
p_{n}=p_{s}=\frac{\sigma}{\sigma-1}=\bar{p}, \quad p_{f}=\left(\frac{\sigma}{\sigma-1}\right) \frac{1}{\delta}=\bar{p} \frac{1}{\delta} .
$$

In order to simplify the notation, I define $\xi=\delta^{\sigma-1}$. As a result, the CES-price indices for the manufacturing goods in the three regions can be derived as 


$$
P_{n}=\bar{p}\left(\lambda+(1-\lambda) \phi_{u}+n \phi_{f} \xi\right)^{\frac{1}{1-\sigma}}, P_{s}=\bar{p}\left(\lambda \phi_{u}+(1-\lambda)+n \phi_{f} \xi\right)^{\frac{1}{1-\sigma}}
$$

and

$$
P_{f}=\bar{p}\left(\phi_{f}+n \xi\right)^{\frac{1}{1-\sigma}},
$$

where $\phi_{f}<\phi_{u} \equiv \tau_{u}^{1-\sigma} \leq 1$ and $\phi_{f} \equiv \tau_{f}^{1-\sigma}$ are parameters which are inversely related to trade costs. The two parameters capture the freeness of trade within the union and between the regions of the union and Foreign country.

Moreover, the wage rate of skilled workers is adjusted in order to ensure zero profits. Therefore, the zero profit condition implies that

$$
X_{i}=(\sigma-1) R_{i}, \quad i=n, s,
$$

and

$$
X_{f}=\delta(\sigma-1) R_{f}
$$

Finally, imposing the condition of zero profits along with the aggregate demand functions (12)-(14) and the price indices and optimal firm prices, the equilibrium skilled wages in every region (i.e. $R_{n}, R_{s}$ and $R_{f}$ ) are obtained as

$$
R_{n}=\frac{\alpha}{\sigma}\left[\frac{\rho+\lambda}{\lambda+(1-\lambda) \phi_{u}+n \phi_{f} \xi}+\frac{\phi_{u}(\rho+(1-\lambda))}{\lambda \phi_{u}+(1-\lambda)+n \phi_{f} \xi}+\frac{\phi_{f}(\rho+n)}{\phi_{f}+n \xi}\right]
$$

and

$$
R_{s}=\frac{\alpha}{\sigma}\left[\frac{\phi_{u}(\rho+\lambda)}{\lambda+(1-\lambda) \phi_{u}+n \phi_{f} \xi}+\frac{\rho+(1-\lambda)}{\lambda \phi_{u}+(1-\lambda)+n \phi_{f} \xi}+\frac{\phi_{f}(\rho+n)}{\phi_{f}+n \xi}\right]
$$

and

$$
R_{f}=\frac{\alpha \xi}{\sigma}\left[\frac{\phi_{f}(\rho+\lambda)}{\lambda+(1-\lambda) \phi_{u}+n \phi_{f} \xi}+\frac{\phi_{f}(\rho+(1-\lambda))}{\lambda \phi_{u}+(1-\lambda)+n \phi_{f} \xi}+\frac{\rho+n}{\phi_{f}+n \xi}\right] .
$$

The short-run equilibrium wages depend on the productivity parameter, the allocation of skilled and unskilled households, the internal and external freeness of trade and the elasticity of substitution between varieties.

\subsection{Market Equilibrium in the Long-Run}

In the long-run skilled workers are allowed to move across regions within the union in response to differences in indirect utilities. This adjustment process over time $t$ is governed by the differential equation

$$
\frac{\mathrm{d} \lambda}{\mathrm{d} t} \equiv \dot{\lambda}=\left(V_{n}-V_{s}\right) \lambda(1-\lambda) .
$$

The differential utility for skilled workers is

$$
V_{n}-V_{s}=\left(R_{n}-R_{s}\right)-\alpha \ln \left(\frac{P_{n}}{P_{s}}\right) .
$$


It can be expressed in an analytical form for general trade costs as

$$
\begin{aligned}
V_{n}-V_{s}=\frac{\alpha}{\sigma}[ & \left.\frac{(\rho+\lambda)\left(1-\phi_{u}\right)}{\left(\lambda+(1-\lambda) \phi_{u}+n \phi_{f} \xi\right)}-\frac{(\rho+1-\lambda)\left(1-\phi_{u}\right)}{\left((1-\lambda)+\lambda \phi_{u}+n \phi_{f} \xi\right)}\right] \\
& -\alpha \ln \left(\frac{\left(\lambda+(1-\lambda) \phi_{u}+n \phi_{f} \xi\right)}{\left((1-\lambda)+\lambda \phi_{u}+n \phi_{f} \xi\right)}\right)^{\frac{1}{1-\sigma}}= \\
= & \frac{\alpha\left(1-\phi_{u}\right)}{\sigma}\left(\frac{M_{n}}{Q_{n}}-\frac{M_{s}}{Q_{s}}\right)-\frac{\alpha}{1-\sigma} \ln \left(\frac{Q_{n}}{Q_{s}}\right)
\end{aligned}
$$

with market sizes

$$
M_{n}=\rho+\lambda, \quad M_{s}=\rho+1-\lambda,
$$

and potentials

$$
Q_{n}=\lambda+(1-\lambda) \phi_{u}+n \phi_{f} \xi, \quad Q_{s}=(1-\lambda)+\lambda \phi_{u}+n \phi_{f} \xi .
$$

In Equation (27), the external freeness of trade $\left(\phi_{f}\right)$, the productivity parameter $(\xi)$ and the number of skilled workers located in Foreign country $(n)$ can be merged into a new parameter $C=n \xi \phi_{f}$. In this case, Equation (27) is algebraically identical to that in a framework without considering regional heterogeneity in labor productivity such as in Brülhart et al. [5]. The interesting part is the economic interpretation of the relative productivity as well as the analytical specification of all agglomeration and dispersion forces in the market.

A symmetric allocation of the mobile factor, i.e. $\lambda=1 / 2$, is always a long-run equilibrium in this model. It can be easily seen that $\lambda=1 / 2$ always leads to a long-run equilibrium since $V_{n}-V_{s}=0$. However, due to the agglomeration forces, this equilibrium is not necessarily stable. In order to evaluate the stability of the symmetric allocation, I evaluate the sign of the derivative

$$
\Delta V^{\prime}=\left[\frac{\mathrm{d}\left(V_{n}-V_{s}\right)}{\mathrm{d} \lambda}\right]_{\lambda=1 / 2}=S L+D L-C E .
$$

The outcome of the derivative in (30) can be split into three different market forces: the supply and the demand linkage (agglomeration forces), and the competition effect (dispersion force). The analytical specification and determination of the market forces are essential in the current work. They show how changes in relative importance between Domestic and Foreign country are likely to affect the internal distribution of economic activity within Domestic country. The supply linkage $(S L)$ says that the region with the higher share of skilled workers has a large manufacturing sector. As a result, the price index of the manufacturing aggregate is lower in that region. I obtain the SL evaluating the derivative of the logarithmic ratio of price indices between South and North with respect to the size of skilled workers in North at the symmetric allocation. Let $\bar{M}=\left.M_{n}\right|_{\lambda=1 / 2}=\left.M_{s}\right|_{\lambda=1 / 2}=\rho+1 / 2 \quad$ and $\quad \bar{Q}=\left.Q_{n}\right|_{\lambda=1 / 2}=\left.Q_{s}\right|_{\lambda=1 / 2}=1 / 2\left(1+\phi_{u}\right)+C$. Then,

$$
S L=\left[\frac{\mathrm{d}\left[\alpha \ln \left(P_{s} / P_{n}\right)\right]}{\mathrm{d} \lambda}\right]_{\lambda=1 / 2}=\frac{2 \alpha\left(1-\phi_{u}\right)}{(\sigma-1) \bar{Q}}=\frac{4 \alpha\left(1-\phi_{u}\right)}{(\sigma-1)\left(\left(1+\phi_{u}\right)+2 C\right)} .
$$


The demand linkage $(D L)$ says that an increase in the share of skilled workers located in North implies a large local market. Therefore, the relative profitability in this market increases. This implies that the wage differential between North and South (i.e. $R_{n}-R_{s}$ ) rises. I obtain the demand linkage evaluating the derivative of the wage differential with respect to $\lambda$ at the symmetric allocation keeping the market potentials constant, in order to isolate the market size effect. Thus,

$$
\begin{aligned}
D L & =\left[\frac{\mathrm{d}\left(R_{n}\left(M_{n}, M_{s}, Q_{n}, Q_{s}\right)-R_{s}\left(M_{n}, M_{s}, Q_{n}, Q_{s}\right)\right)}{\mathrm{d} \lambda}\right]_{\lambda=1 / 2 ;\left(Q_{n}, Q_{s} \text { fixed }\right)} \\
& =\frac{2 \alpha\left(1-\phi_{u}\right)}{\sigma \bar{Q}}=\frac{4 \alpha\left(1-\phi_{u}\right)}{\sigma\left(\left(1+\phi_{u}\right)+2 C\right)} .
\end{aligned}
$$

Finally, the competition effect $(C E)$ comes from the fact that a movement of firms from South to North increases competition on products that are produced in North for given expenditures. I obtain the competition effect evaluating the derivative of the wage differential with respect to $\lambda$ at the symmetric allocation, keeping the market sizes constant. Thus,

$$
\begin{aligned}
C E & =\left[\frac{d\left(R_{n}\left(M_{n}, M_{s}, Q_{n}, Q_{s}\right)-R_{s}\left(M_{n}, M_{s}, Q_{n}, Q_{s}\right)\right)}{\mathrm{d} \lambda}\right]_{\lambda=1 / 2 ;\left(M_{n}, M_{s} \text { fixed }\right)} \\
& =\frac{2 \alpha\left(1-\phi_{u}\right)^{2} \bar{M}}{\sigma \bar{Q}^{2}}=\frac{4 \alpha(1+2 \rho)\left(1-\phi_{u}\right)^{2}}{\sigma\left(\left(1-\phi_{u}\right)+2 C\right)^{2}} .
\end{aligned}
$$

The symmetric allocation constitutes a stable long-run equilibrium when (30) is negative. I consider the absolute value of all agglomeration and dispersion forces although they have different impacts on the stability of the long-run equilibrium. More specifically, both supply and demand linkages force the symmetric allocation to become an unstable long-run equilibrium while the competition effect is the stabilizing effect, being responsible for the stability of the symmetric allocation in the model.

Falling external trade barriers increase the market potentials (i.e. $\bar{Q}$ goes up); this has a negative impact on all market forces, according to Equations (31)-(33). Moreover, as $\xi$ goes up Foreign market becomes more productive. All agglomeration and dispersion forces decline in absolute terms. A decrease in relative productivity has an identical impact on the market forces as the one that comes from falling external trade barriers. Since an increase in the composed parameter $C$ has a negative impact on all market forces, it is interesting to study which effect dominates and why. In order to simplify the analysis, I consider the following monotonic transformations of the three market forces. Let $\widetilde{S L}=S L f$, $\widetilde{D L}=D L f$ and $\widetilde{C E}=C E f$, with $f=\sigma \bar{Q} /\left[2 \alpha\left(1-\phi_{u}\right)\right]>0$. Then, the agglomeration effect $(\mathrm{AE})$ is given as

$$
A E=\widetilde{S L}+\widetilde{D L}=\frac{2 \sigma-1}{\sigma-1},
$$

and the dispersion effect $(D E)$ is given as 


$$
D E=\widetilde{C E}=\frac{\left(1-\phi_{u}\right)(1+2 \rho)}{\left(1+\phi_{u}\right)+2 C} .
$$

Obviously, the agglomeration effect $(A E)$ depends on $\sigma$, and the dispersion effect $(D E)$ depends on all other parameters of interest. The $A E$ is strictly decreasing in $\sigma$ (i.e. $\mathrm{d} A E / \mathrm{d} \sigma<0)$. The $D E$ is strictly decreasing in $\phi_{u}$ and $C$; it also increases in $\rho$. Thus, an increase in $\phi_{u}$ and/or $C$ results in internal agglomeration since it reduces the $D E$ without affecting the $A E$. Additionally, an increase in $\sigma$ and/or $\rho$ favors internal dispersion since the former reduces the $A E$, and the latter increases the $D E$. Finally, the dependence of $C$ on $\sigma$ is neglected since an increase in $\sigma$ reduces $C$. This adds another dispersing effect, enhancing the initial effect of $\sigma$.

In order to study where the symmetric allocation constitutes a long-run stable equilibrium, I evaluate the sign of expression (30). The outcome of the derivative in (30) consists of the three market forces. According to the Equations (31)-(33), the magnitude of these three forces varies with the level of trade freeness. Figure 1 illustrates how this magnitude is affected for different values of the internal and external freeness of trade. I am interested in specifying the two critical levels of the internal freeness of trade for which the derivative in (30) becomes zero. At those two break points, the agglomeration forces (i.e. $S L$ and $D L$ ) are canceled out by the dispersion force (i.e. $C E$ ).

For values between these two break points, expression (30) is positive. This implies that the agglomeration forces dominate the dispersion force. As a result, the economic activity within the union is concentrated in one region. Between the autarky point and the first break point, the dispersion force dominates the agglomeration forces. Therefore, (30) is negative and thus dispersion of skilled workers takes place within the union.

It can be seen graphically that these two critical levels of the internal freeness of trade are obtained by the intersection of the yellow curve with the level where

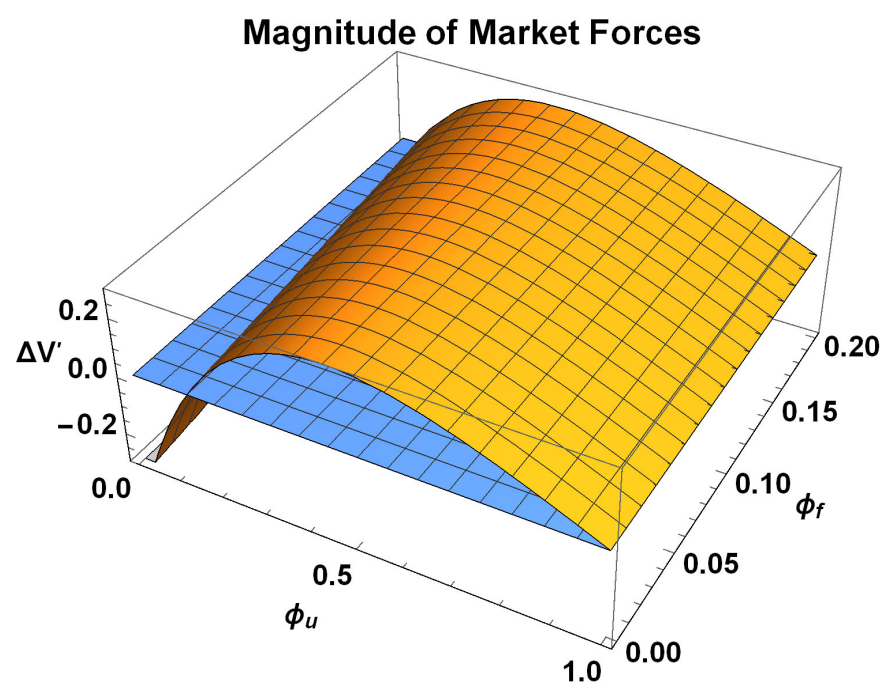

Figure 1. Magnitude of agglomeration and dispersion forces. 
expression (30) is equal to zero. After obtaining those two break points, I study how they depend on the rest of the parameters mainly focusing on the external freeness of trade and the relative productivity. The first break point is trivial since it is constant and equal to one. The second break point is the interesting one since it depends on the parameters of interest. The analytical expressions are

$$
\phi_{t r}=1 \text {, }
$$

and

$$
\phi_{c r}=\frac{(2 \rho-4 C-1) \sigma+2(C-\rho)}{(3+2 \rho) \sigma-2(1+\rho)} .
$$

It can be seen that the numerator of $\phi_{c r}$ is always lower than its denominator since $\sigma>1$. This implies that $\phi_{c r}$ is always smaller than one. Let $N$ and $D$ denote the numerator and denominator of $\phi_{c r}$, respectively. Obviously, the denominator is positive. In addition, $D-N=3 \sigma-2+4 C \sigma+\sigma-2 C>0 \Leftrightarrow 4 \sigma>2$ which holds since $\sigma>1$. Thus, the numerator is smaller than the denominator, possibly even negative. In order to avoid the "black hole" case where $\phi_{c r}$ is negative and only concentration takes place, the numerator must be positive too.

Lemma 1: NBH ("no black hole") holds if and only if the two conditions $(\alpha)$ : $2 \rho>1+4 C$ and $(\beta): \sigma>\frac{2(\rho-C)}{2 \rho-4 C-1}$ hold simultaneously.

Proof.

If $\sigma>\frac{2(\rho-C)}{2 \rho-4 C-1}$ and $2 \rho>1+4 C$, then $N>0$. Now, let the NBH condition hold. Then,

$$
\sigma(2 \rho-4 C-1)>2(\rho-C)
$$

Let $\rho<C$, then $2 \rho-4 C-1<2 \rho-2 C<0$. Thus, (38) is violated. Thus, $\rho \geq C$, and hence $2 \rho-4 C-1>0$. But then (38) implies $\beta$.

The first condition implies that the "black hole" case is avoided when the composite parameter $C$ does not take high values. This can happen in two cases. First, in the case where the trade between the regions of the union and Foreign country is not completely free; second, when the relative productivity is not very small (i.e. the union is significantly more productive than Foreign country). The second condition implies that the elasticity of substitution between varieties should be above a particular threshold. This means that individuals should not have very high preferences for diversity. The following proposition summarizes how a change in the composed $C$, the proportion of unskilled workers $\rho$, and the elasticity of substitution affects the critical break point $\phi_{c r}$.

Proposition 1: The critical break point $\phi_{c r}$

1) decreases in the composed parameter $C$,

2) increases in the proportion of unskilled workers $\rho$ and the elasticity of substitution $\sigma$.

Proof.

1) 


$$
\frac{\mathrm{d} \phi_{c r}}{\mathrm{~d} C}=\frac{2-4 \sigma}{\sigma(3+2 \rho)-2(1+\rho)}<0 .
$$

The numerator is negative and the denominator is positive. Thus, the sign of the derivative is negative.

2)

$$
\frac{\mathrm{d} \phi_{c r}}{\mathrm{~d} \rho}=\frac{2(\sigma-1)(D-N)}{D^{2}}>0 .
$$

Expression (40) is positive since $D>N$.

Now, let $r=2 \rho-4 C-1>0$. Then $\frac{\mathrm{d} \phi_{c r}}{\mathrm{~d} \sigma}>0$ iff:

$$
\left[r-2 C^{\prime}(\sigma)(2 \sigma-1)\right][\sigma(2 \rho+3)-2(\rho+1)]>(2 \rho+3) r(\sigma-\underline{\sigma}),
$$

with $\underline{\sigma}=\frac{2(\rho-C)}{r}>1$.

The productivity of the union is greater than that of Foreign country by assumption (i.e. $0<\delta<1$ ). This implies $C^{\prime}(\sigma)<0$. Then,

$$
\left[r-2 C^{\prime}(\sigma)(2 \sigma-1)\right][\sigma(2 \rho+3)-2(\rho+1)]>r[\sigma(2 \rho+3)-2(\rho+1)] \text {. }
$$

Now,

$$
r[\sigma(2 \rho+3)-2(\rho+1)]>(2 \rho+3) r(\sigma-\underline{\sigma}),
$$

which holds. Thus, (42) and (43) implies (41) and hence $\frac{\mathrm{d} \phi_{c r}}{\mathrm{~d} \sigma}>0$.

Falling external trade barriers reduce all market forces and, according to proposition 1, decrease the critical break point, too. This implies that the dispersion force falls faster than the agglomeration forces. Thus, skilled workers are concentrated in one region within the union. The impact that comes from a decrease in relative productivity is identical to the one that comes from falling external trade barriers. More specifically, a reduction in relative productivity favors internal agglomeration of the mobile factor. The same impact evolves when the size of skilled workers located in Foreign country goes up. Intuitively, a decrease in relative productivity compensates for the trade barriers between the regions of the union and Foreign country.

Finally, an increase in the elasticity of substitution between varieties implies low preferences for diversity. This leads to weaker economies of scale at the firm level $(1 / \sigma)$. As a result, less agglomeration of skilled workers within the union takes place. Equations (31)-(33) show that the number of unskilled immobile workers affects only the competition effect. Thus, an increase of unskilled immobile workers raises the $\mathrm{CE}$ in absolute terms. This leads to dispersion of skilled labor within the union.

\subsection{Robustness}

\subsubsection{Short-Run Market Equilibrium}

The quasi-linearity assumption is used for computational reasons. In fact, this choice does not take into account the income effect. In this section, I study the 
importance of the income effect by considering a Cobb-Douglas utility function. Let the preferences of a typical household located in region $i$ be

$$
U_{i}=C_{X}^{i \alpha} C_{A}^{i 1-\alpha}, \quad i=n, s, f .
$$

Each household maximizes its utility subject to its budget constraint (3). It derives the new demand functions for the manufacturing aggregate and the agricultural good as

$$
C_{X}^{i}=\frac{\alpha Y_{i}}{P_{i}}, \quad C_{A}^{i}=(1-\alpha) Y_{i}, \quad i=n, s, f .
$$

The indirect utility is given by

$$
\omega_{i}=\beta \frac{Y_{i}}{P_{i}^{\alpha}}, \quad \beta=\alpha^{\alpha}(1-\alpha)^{1-\alpha}, \quad i=n, s, f .
$$

Moreover, the new demand functions of a representative household located in North for manufacturing varieties are obtained as

$$
x_{n n}^{\prime}=\alpha p_{n}^{-\sigma} P_{n}^{\sigma-1} Y_{n}, \quad x_{n s}^{\prime}=\alpha\left(\tau_{u} p_{s}\right)^{-\sigma} P_{n}^{\sigma-1} Y_{n}, x_{n f}^{\prime}=\alpha\left(\tau_{f} p_{f}\right)^{-\sigma} P_{n}^{\sigma-1} Y_{n} .
$$

Similarly, demand functions

$$
x_{s n}^{\prime}=\alpha\left(\tau_{u} p_{n}\right)^{-\sigma} P_{s}^{\sigma-1} Y_{s}, \quad x_{s s}^{\prime}=\alpha p_{s}^{-\sigma} P_{s}^{\sigma-1} Y_{s}, \quad x_{s f}^{\prime}=\alpha\left(\tau_{f} p_{f}\right)^{-\sigma} P_{s}^{\sigma-1} Y_{s}
$$

are obtained for a typical household located in South. Finally, the new demand functions of a representative household located in Foreign country are

$$
x_{f n}^{\prime}=\alpha\left(\tau_{f} p_{n}\right)^{-\sigma} P_{f}^{\sigma-1} Y_{f}, \quad x_{f s}^{\prime}=\alpha\left(\tau_{f} p_{s}\right)^{-\sigma} P_{f}^{\sigma-1} Y_{f}, \quad x_{f f}^{\prime}=\alpha p_{f}^{-\sigma} P_{f}^{\sigma-1} Y_{f} .
$$

Combining the new aggregate demand functions together with the price indices and optimal firm prices (see Section 2.3), the new short-run equilibrium skilled wages in every region (i.e. $R_{n}^{\prime}, R_{s}^{\prime}$ and $R_{f}^{\prime}$ ) are obtained after solving the following system of equations for $R_{n}^{\prime}, R_{s}^{\prime}$ and $R_{f}^{\prime}$, respectively.

$$
R_{n}^{\prime}=\frac{\alpha}{\sigma}\left[\frac{\rho+\lambda R_{n}^{\prime}}{\lambda+(1-\lambda) \phi_{u}+n \phi_{f} \xi}+\frac{\phi_{u}\left(\rho+(1-\lambda) R_{s}^{\prime}\right)}{\lambda \phi_{u}+(1-\lambda)+n \phi_{f} \xi}+\frac{\phi_{f}\left(\rho+n R_{f}^{\prime}\right)}{\phi_{f}+n \xi}\right]
$$

and

$$
R_{s}^{\prime}=\frac{\alpha}{\sigma}\left[\frac{\phi_{u}\left(\rho+\lambda R_{n}^{\prime}\right)}{\lambda+(1-\lambda) \phi_{u}+n \phi_{f} \xi}+\frac{\rho+(1-\lambda) R_{s}^{\prime}}{\lambda \phi_{u}+(1-\lambda)+n \phi_{f} \xi}+\frac{\phi_{f}\left(\rho+n R_{f}^{\prime}\right)}{\phi_{f}+n \xi}\right]
$$

and

$$
R_{f}^{\prime}=\frac{\alpha \xi}{\sigma}\left[\frac{\phi_{f}\left(\rho+\lambda R_{n}^{\prime}\right)}{\lambda+(1-\lambda) \phi_{u}+n \phi_{f} \xi}+\frac{\phi_{f}\left(\rho+(1-\lambda) R_{s}^{\prime}\right)}{\lambda \phi_{u}+(1-\lambda)+n \phi_{f} \xi}+\frac{\rho+n R_{f}^{\prime}}{\phi_{f}+n \xi}\right] .
$$

\subsubsection{Long-Run Market Equilibrium}

In the long-run skilled workers are allowed to move within the union in response to their utility differences. Instead of considering the utility differential, it is more convenient to consider the ratio of the indirect utilities. Thus, 


$$
\frac{\omega_{n}}{\omega_{s}}=\frac{R_{n}}{R_{s}}\left(\frac{P_{s}}{P_{n}}\right)^{\alpha}
$$

The symmetric allocation remains a long-run equilibrium in this model since it can be shown that $\omega_{n} / \omega_{s}=1$ at $\lambda=1 / 2$. However, the symmetry can be either a stable or an unstable equilibrium. In order to study the stability of the symmetric equilibrium, I evaluate the sign of the derivative

$$
\Delta \omega^{\prime}=\left[\frac{\mathrm{d}\left(\omega_{n} / \omega_{s}\right)}{\mathrm{d} \lambda}\right]_{\lambda=1 / 2}=\left[\frac{\mathrm{d}\left(R_{n} / R_{s}\right)}{\mathrm{d} \lambda}\right]_{\lambda=1 / 2}+\left[\frac{\mathrm{d}\left(P_{s} / P_{n}\right)^{\alpha}}{\mathrm{d} \lambda}\right]_{\lambda=1 / 2} .
$$

In the current version of the model, the market potentials are identical to those given by Equation (29). However, the new market sizes depend on the skilled nominal wage rates. They are defined as

$$
M_{n}^{\prime}=\rho+\lambda R_{n}^{\prime}, \quad M_{s}^{\prime}=\rho+(1-\lambda) R_{s}^{\prime}, \quad M_{f}^{\prime}=\rho+n R_{f}^{\prime},
$$

for North, South and Foreign country, respectively. In Equation (54), the first term on the right hand side denotes the demand linkage and the competition effect together. The second term is the supply linkage. It is the same as the one given by Equation (31). In the current model, the demand linkage is slightly different. It is given by

$$
D L=\frac{4 \alpha\left(1-\phi_{u}\right)}{(\sigma-\alpha)+(\sigma+\alpha) \phi_{u}+2 n \phi_{f} \xi} .
$$

In addition, the absolute value of the competition effect is given by

$$
C E=D L \frac{\sigma\left(1-\phi_{u}\right)\left(2 n \xi(\sigma-\alpha)+(\alpha+2 \sigma) \phi_{f}\right)}{\alpha\left(2 n \xi(\sigma-\alpha)\left(1+\phi_{u}\right)+3 \sigma\left(1+\phi_{u}\right) \phi_{f}+2 n \xi(2 \alpha+\sigma) \phi_{f}^{2}\right)} .
$$

The next proposition summarizes how the market forces change as the external freeness of trade improves.

Proposition 2: All market forces decrease in the external freeness of trade $\phi_{f}$.

Proof. From (31), it follows that $\frac{\mathrm{d} S L}{\mathrm{~d} \phi_{f}}<0$. Similarly, from (56) it is obvious that $\frac{\mathrm{d} D L}{\mathrm{~d} \phi_{f}}<0$.

Let, $A=2 n \xi(\sigma-\alpha), \quad B=(\alpha+2 \sigma), \quad \Gamma=2 n \xi(\sigma-\alpha)\left(1+\phi_{u}\right), \quad \Delta=3 \sigma\left(1+\phi_{u}\right)$ and $E=2 n \xi(2 \alpha+\sigma)$. Then, I consider the first derivative of the following monotonic transformation with respect to $\phi_{f}$ as

$$
\frac{\mathrm{d}\left(\frac{\alpha C E}{\sigma\left(1-\phi_{u}\right)}\right)}{\mathrm{d} \phi_{f}}=\frac{\mathrm{d} D L}{\mathrm{~d} \phi_{f}} \frac{A+B \phi_{f}}{\Gamma+\Delta \phi_{f}+E \phi_{f}^{2}}+D L \frac{-B E \phi_{f}^{2}-2 A E \phi_{f}+B \Gamma-A \Delta}{\left(\Gamma+\Delta \phi_{f}+E \phi_{f}^{2}\right)^{2}}<0,
$$

since $B \Gamma-A \Delta<0$ and $\frac{\mathrm{d} D L}{\mathrm{~d} \phi_{f}}<0$. 
Proposition 2 shows that an improvement in the external freeness of trade reduces all market forces. The reduction of both SL and DL tends to make the symmetry a stable long-run equilibrium while the reduction of $\mathrm{CE}$ forces the symmetry to become an unstable long-run equilibrium. Due to the complexity of the equations that describe the market forces, I cannot show which force dominates. When the agglomeration forces dominate the dispersion force, the symmetric allocation is not a stable long-run equilibrium. On the contrary, when the dispersion force dominates the agglomeration forces, the symmetry constitutes a stable long-run equilibrium. I study this case numerically considering different values for the basic parameters of the model (i.e. $\alpha, \sigma, n, \xi$ ).

The selection of the parameter values is based on the work of Head and Mayer [16]. More specifically, when the industrial sector stands for all tradable goods in the economy, estimations of $\sigma$ vary between 3 and 5, whereas $\alpha$ takes values between 0.5 and 0.8. By contrast, when this sector is a specific industry, $\sigma$ sharply rises because varieties are now much better substitutes than in the aggregate level. A value of $\sigma$ close to 7 is then acceptable. In that case, $\alpha$ typically takes a value lower than 0.2 , which approximately corresponds to the share of the manufacturing goods in a developed economy. The productivity parameter $\xi$ takes values between 0 and 1 . Also, $n$ is arbitrarily chosen between 1 and 5 .

I consider the effect of reducing the external trade barriers on the spatial distribution of the union's economic activity. For given values of the parameters $\alpha, \sigma, n, \xi$, I set (54) equal to zero and solve it numerically for the values of the critical break point over a range of values of $\phi_{f} \in[0,1]$. The results are obtained for a specific parameter profile. In particular, I consider that $\sigma \in\{4,7\}$, $\alpha \in\{0.2,0.6\}, \xi \in\{0.3,0.5,0.9\}$ and $n \in\{1,3,5\}$. After taking into account all 36 possible combinations of the parameter profile, I find that the results in Section 2.4 are robust, as falling external trade barriers lead to internal agglomeration of the economic activity. For example, Figure 2 shows how the critical break point changes with respect to the external freeness of trade for $\sigma=4$,

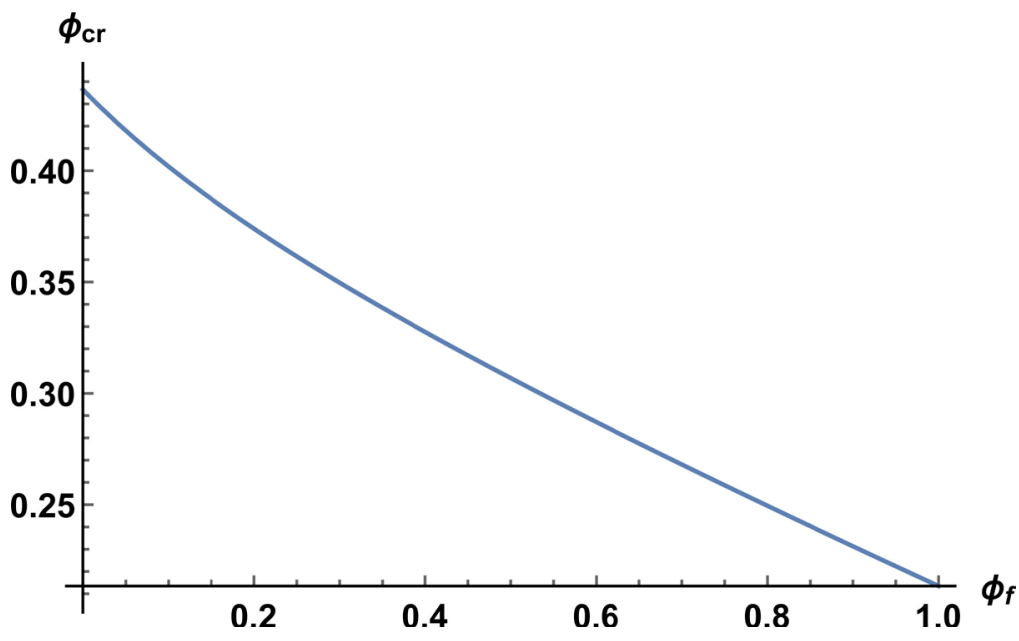

Figure 2. $\phi_{c r}$ and external freeness of trade. 
$\alpha=0.6, n=1$ and $\xi=1 / 2$.

After considering the income effect, I show that the critical break point falls as long as the external freeness of trade increases. This result implies that in the Cobb-Douglas case, falling external trade barriers lead to internal agglomeration of the economic activity. This result is in accordance with the prediction of the model under the quasi-linearity assumption.

\section{Welfare}

In this section, I conduct a welfare analysis considering a Utilitarian concept where a social planner is assumed to maximize the un-weighted sum of individual indirect utilities. I use a Utilitarian approach due to the fact that under the assumption of quasi-linear preferences, the marginal utility of income for all agents in the economy is equal to one. This implies that income redistributions do not affect the aggregate welfare.

Let $I_{n}^{u}, I_{s}^{u}$ and $I_{f}^{u}$ denote the indirect utility of an unskilled immobile worker in North, South and Foreign country, respectively. Similarly, $I_{n}^{s}$ and $I_{s}^{s}$ denote the indirect utility of a skilled mobile worker located in North and South. $I_{f}^{s}$ is the indirect utility of a skilled immobile worker located in Foreign country. Therefore, I define the Utilitarian social welfare function as

$$
\Omega(\lambda)=\lambda I_{n}^{s}+(1-\lambda) I_{s}^{s}+n I_{f}^{s}+\rho\left(I_{n}^{u}+I_{s}^{u}+I_{f}^{u}\right) .
$$

There are two sources of inefficiency in the model. The first comes from the fact that the manufacturing sector is a monopolistic Dixit-Stiglitz sector. As a result, firms have market power and their mill prices are not equal to their marginal costs. A constant mark-up is added, which depends on the elasticity of substitution between varieties. The second source comes from the decision of a skilled worker whether to migrate or not, without considering the effects of his decision on market prices. As a result, a change in market prices influences the welfare of all other agents in the economy.

In order to compute the optimal social allocation, I replace the analytical expressions for $I_{n}^{s}, I_{s}^{s}, I_{f}^{s}, I_{n}^{u}, I_{s}^{u}$ and $I_{f}^{u}$ into the social welfare function (59) above. Then, it can be shown that the first derivative of the social welfare function with respect to the share of skilled workers in North (i.e. $d \Omega / d \lambda$ ) is equal to zero at $\lambda=1 / 2$. Note that $\lambda=1 / 2$ can be either a welfare maximum or a minimum. Furthermore, it is possible that the social welfare function can have more extrema for different values of $\lambda$.

Following the work of Pflüger and Südekum [14] it is enough to calculate the second derivative of $\Omega$ with respect to $\lambda$ and evaluate it at $\lambda=1 / 2$. This is going to show us when the social planner chooses either the symmetric allocation $(\lambda=1 / 2)$ or the (full or partial) agglomeration. Thus,

$$
\Omega^{\prime \prime}=\left[\frac{\mathrm{d}^{2} \Omega}{\mathrm{d} \lambda^{2}}\right]_{\lambda=\frac{1}{2}}=\frac{4 \alpha\left(1-\phi_{u}\right)\left(\left(1-2 \rho+(3+2 \rho) \phi_{u}\right)+4 C\right)}{(\sigma-1)\left(\left(1+\phi_{u}\right)+2 C\right)^{2}} .
$$


The symmetric allocation constitutes a global maximum when $\Omega^{\prime \prime}<0$. The (full or partial) agglomeration, however, is chosen when $\Omega^{\prime \prime}>0$. Setting expression (60) equal to zero and solving for $\phi_{u}$, two critical values are obtained as

$$
\phi_{t r}^{s c}=1
$$

and

$$
\phi_{c r}^{s c}=\frac{2 \rho-4 C-1}{3+2 \rho} .
$$

I call the bifurcation point $\phi_{c r}^{s c}$ social break point, which occurs at the level of the internal freeness of trade, at which the symmetry $\lambda=1 / 2$ is no longer the social optimum outcome. From lemma 1 it holds that $2 \rho>1+4 C$. This implies that the social break point is greater than zero. It can also be shown that the denominator of $\phi_{c r}^{s c}$ is larger than its numerator. Hence, $\phi_{c r}^{s c}$ is always smaller than one. The next proposition summarizes how the market equilibrium outcome deviates from the social optimal outcome.

Proposition 3: The market critical break point is lower than the social break point i.e. $\phi_{c r}<\phi_{c r}^{s c}$.

Proof. It follows from subtracting the social break point from the market critical break point as given by (62) and (37). Thus,

$$
\phi_{c r}-\phi_{c r}^{s c}=-\frac{2(1+C)(1+2 \rho)}{(3+2 \rho)((3+2 \rho) \sigma-2(\rho+1))}<0,
$$

because $(3+2 \rho)((3+2 \rho) \sigma-2(\rho+1))>0$ since $\sigma>1$.

The fact that the social break point is lower than the market critical break point means that less agglomeration of skilled workers within the union is socially preferred. For $\phi_{u} \in\left(\phi_{c r}, \phi_{c r}^{s c}\right)$ the market equilibrium outcome favors internal agglomeration although internal dispersion is socially preferred. For $\phi_{u}<\phi_{c r}$ and $\phi_{u}>\phi_{c r}^{s c}$ the equilibrium outcome coincides with the social optimal

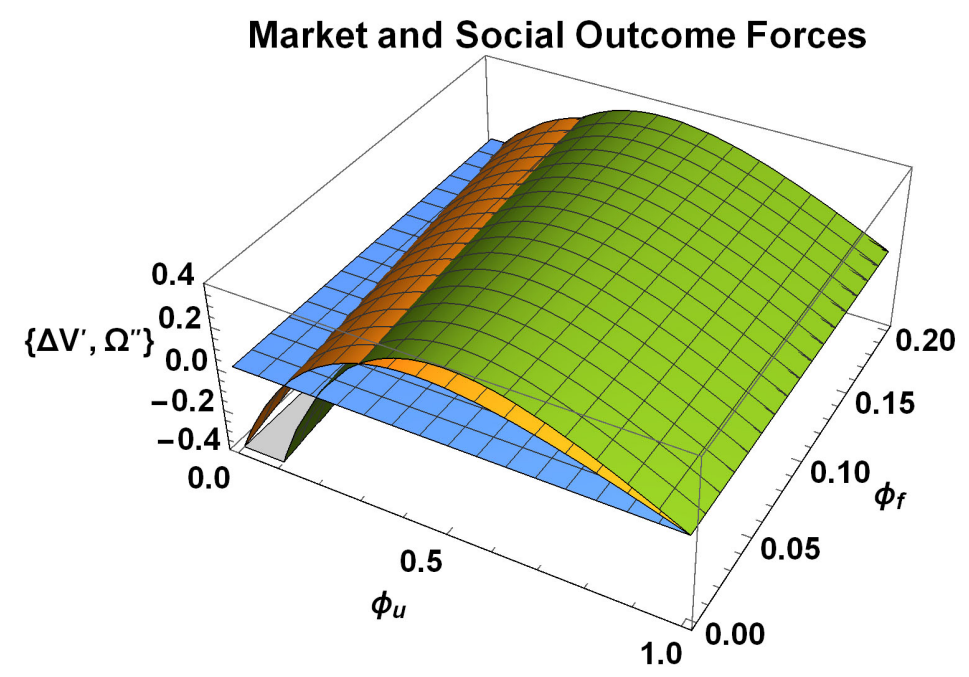

Figure 3. Market and social outcome forces. 
outcome. Both market and social forces are illustrated in Figure 3. The green curve depicts the social outcome forces and the yellow curve represents all market equilibrium forces. Dispersion of skilled workers within the union is socially preferred between the autarky point and the social break point. Between $\phi_{c r}^{s c}$ and $\phi_{t r}^{s c}$ expression (60) is positive. This implies that agglomeration of the economic activity within the union is socially preferred.

Regarding the change of the social break point with respect to the remaining parameters $C, \rho$ and $\sigma$, the results are qualitatively the same as those in proposition 1. More specifically, it can be shown that $\frac{\mathrm{d} \phi_{c r}^{s c}}{\mathrm{~d} C}=-\frac{4}{D}<0$, $\frac{\mathrm{d} \phi_{c r}^{s c}}{\mathrm{~d} \rho}=-\frac{2(D-N)}{D^{2}}>0$ and $\frac{\mathrm{d} \phi_{c r}^{s c}}{\mathrm{~d} \sigma}=\phi_{C} C_{\sigma}>0$. Therefore, the comparative static analysis for the point $\phi_{c r}^{s c}$ is qualitatively the same as the one for the point $\phi_{c r}$ and the basic intuitions still hold. The mobility of skilled workers within the union affects 1) the skilled wage rates in the entire economy, and 2) the price indices in the union. The price index in Foreign country, however, is not affected. As a result, with constant wages and unchanged price index, the indirect utility of unskilled workers located in Foreign country is not affected by any relocation of skilled workers within the union.

\section{Consumer Taste Bias}

As a matter of fact, there are broader cultural, traditional and political dimensions of globalization. In this section, I study the multidimensional bias of household taste that mainly comes from the different culture, religious, political and traditional aspects across regions. Due to these differences, in some cases, individuals have the tendency to put more value on products that are produced in their home region. In other cases, individuals put more value on goods, services and other cultural elements which come from another region. In order to take these idiosyncratic differences in consumer taste into account, I rewrite the CES utility in (2) for a typical household located in North as

$$
C_{X}^{n}=\left[\int_{V_{n}}\left(A_{h} l_{n}(v)\right)^{\frac{\sigma-1}{\sigma}} \mathrm{d} v+\int_{V_{s}}\left(A_{p} l_{n}(v)\right)^{\frac{\sigma-1}{\sigma}} \mathrm{d} v+\int_{V_{f}}\left(A_{f} l_{n}(v)\right)^{\frac{\sigma-1}{\sigma}} \mathrm{d} v\right]^{\frac{\sigma}{\sigma-1}},
$$

where $A_{i}$ is a utility shifter ("attractiveness") and can be interpreted as a monadic quality shifter. In particular, $A_{h}$ is the "attractiveness" of all products that are produced in the home region, $A_{p}$ denotes the "attractiveness" of all products that are produced in the other region of the union called partner region, and $A_{f}$ is the quality shifter of the products that are produced in the other country. Similarly, the CES utility of a typical household located in South is

$$
C_{X}^{s}=\left[\int_{V_{n}}\left(A_{p} l_{s}(v)\right)^{\frac{\sigma-1}{\sigma}} \mathrm{d} v+\int_{V_{s}}\left(A_{h} l_{s}(v)\right)^{\frac{\sigma-1}{\sigma}} \mathrm{d} v+\int_{V_{f}}\left(A_{f} l_{s}(v)\right)^{\frac{\sigma-1}{\sigma}} \mathrm{d} v\right]^{\frac{\sigma}{\sigma-1}} .
$$

Finally, for a typical household located in Foreign country the CES utility is 


$$
C_{X}^{f}=\left[\int_{V_{n} \cup V_{s}}\left(A_{f} l_{f}(v)\right)^{\frac{\sigma-1}{\sigma}} \mathrm{d} v+\int_{V_{f}}\left(A_{h} l_{f}(v)\right)^{\frac{\sigma-1}{\sigma}} \mathrm{d} v\right]^{\frac{\sigma}{\sigma-1}} .
$$

In the light of isomorphism, the wage differential in (27) can be rewritten for the new values $\tilde{\phi}_{u}=\frac{\psi_{p}}{\psi_{h}} \phi_{u}$ and $\tilde{\phi}_{f}=\frac{\psi_{f}}{\psi_{h}} \phi_{f} \quad$ with $\quad \psi_{h}=A_{h}^{\sigma-1}, \psi_{p}=A_{p}^{\sigma-1}$ and $\psi_{f}=A_{f}^{\sigma-1}$. The symmetric allocation of skilled mobile workers $(\lambda=1 / 2)$ is a long-run equilibrium in this model. I study the stability of the symmetric allocation following the same procedure as in Section 2.4. The new break points are obtained as

$$
\phi_{c r 1}=\frac{1}{\Psi_{p}}
$$

and

$$
\phi_{c r 2}=\frac{(2 \rho-4 \Gamma-1) \sigma+2(\Gamma-\rho)}{\Psi_{p}((3+2 \rho) \sigma-2(1+\rho))},
$$

where $\Psi_{p}=\frac{\psi_{p}}{\psi_{h}}$ and $\Gamma=n \Psi_{f} \phi_{f}$, with $\Psi_{f}=\frac{\psi_{f}}{\psi_{h}}$.

The first break point $\phi_{c r 1}$ is positive. Based on lemma 1, a modified NBH holds if and only if $(\alpha): 2 \rho>1+4 \Gamma$ and $(\beta): \sigma>\frac{2(\rho-\Gamma)}{2 \rho-4 \Gamma-1}$ hold simultaneously. Thus, under these two conditions, $\phi_{c r 2}$ is also greater than zero. Let $\tilde{\phi}_{c r}$ be the critical break point in a model with neither taste bias nor productivity differences. Then, in the light of isomorphism, $\phi_{c r 2}=\frac{\psi_{h}}{\psi_{p}} \tilde{\phi}_{c r}$. Therefore, it is enough $\tilde{\phi}_{c r}<\frac{\psi_{p}}{\psi_{h}}=\Psi_{p}$ for $\phi_{c r 2}$ being less than one.

The ratio $\Psi_{f}=\frac{\psi_{f}}{\psi_{h}}$ shows the relative taste bias between the home region and Foreign country. Similarly, the ratio $\Psi_{p}=\frac{\psi_{p}}{\psi_{h}}$ denotes the taste bias between the two regions of the union. The comparative static analysis for the critical break point $\phi_{c r 2}$ is qualitatively the same as the one for $\phi_{c r}$, in proposition 1. Therefore, it can be shown that $\frac{\mathrm{d} \phi_{c r 2}}{\mathrm{~d} \Gamma}>0, \frac{\mathrm{d} \phi_{c r 2}}{\mathrm{~d} \rho}>0$ and $\frac{\mathrm{d} \phi_{c r 2}}{\mathrm{~d} \sigma}>0$. Moreover, both $\phi_{c r 1}$ and $\phi_{c r 2}$ are strictly decreasing in the composed parameter $\Psi_{p}$ (i.e. $\frac{\mathrm{d} \phi_{c r 1}}{\mathrm{~d} \Psi_{p}}<0$ and $\left.\frac{\mathrm{d} \phi_{c r 2}}{\mathrm{~d} \Psi_{p}}<0\right)$. The impact of $\Psi_{f}$ on the critical break point $\phi_{c r 2}$ is identical to the impact of $\phi_{f}$ on $\phi_{c r 2}$, all else equal; $\Psi_{f}$ does not affect $\phi_{c r 1}$. I consider two cases of taste bias, namely ethnocentrism and xenocentrism. Ethnocentrism underscores the belief that buying foreign made products is unpatriotic. It can harm the domestic economy and this implies that $A_{h}>A_{p}>A_{f}$. On the contrary, xenocentrism is the preference for foreign made products, styles or ideas. This implies that $A_{h}<A_{p}$ and $A_{h}<A_{f}$. 
The critical break point $\phi_{c r 2}$ belongs to the relevant interval of $\phi_{u}$. In the case of ethnocentrism, $\Psi_{p}<1$. This implies that $\phi_{c r 1}$ is greater than one. The symmetric allocation is stable between the autarky point and the critical point $\phi_{c r 2}$. In the interval between the two break points, the symmetry is no longer stable. Thus, the mobile factor agglomerates within the union. Figure 4(a) shows the magnitude of all agglomeration and dispersion forces in the case of ethnocentrism. Intuitively, an increase in $\Psi_{f}$ compensates for the trade barriers between the home region and Foreign country. This shifts the critical break point $\phi_{c r 2}$ to the left. Therefore, a shift of consumer preferences in the union with respect to goods that are produced in Foreign country results in internal agglomeration of the economic activity. Similarly, an increase in $\Psi_{p}$ shifts $\phi_{c r 2}$ to the left. This also results in internal agglomeration.

An interesting result comes from the case of xenocentrism since $\Psi_{p}>1$. Thus, the critical break point $\phi_{c r 1}$ is lower than one. The symmetry constitutes still an unstable long-run equilibrium in the interval between the two break points. It, however, becomes stable 1) between the autarky point and $\phi_{c r 2}$, and 2) between $\phi_{c r 1}$ and the completely free trade point. To see this, let $\Delta V_{*}^{\prime}$ be the counterpart of Equation (30) in a model with taste bias. Then, it can be shown that $\left[\frac{\mathrm{d} \Delta V_{*}^{\prime}}{\mathrm{d} \phi_{u}}\right]_{\phi_{u}=\phi_{c r 1}}=\frac{2 \alpha \Psi_{p}(1-2 \sigma)}{(\Gamma+1)(\sigma-1) \sigma}<0$ since $\sigma>1$. This is a stability proof implying that, for $\phi_{u}>\phi_{c r 1}$, the symmetric allocation constitutes a stable long-run equilibrium in this model. Figure 4(b) shows the magnitude of all agglomeration and dispersion forces in the case of xenocentrism. Dispersion of the mobile factor takes place within the union for small and high values of the internal freeness of trade. For intermediate values of $\phi_{u}$ the symmetry is unstable. Thus, agglomeration of the economic activity occurs within the union. Finally, an increase in $\Psi_{p}$ shifts both $\phi_{c r 1}$ and $\phi_{c r 2}$ to the left. It can be shown that $\frac{\mathrm{d} \phi_{c r 2}}{\mathrm{~d} \Psi_{p}}>\frac{\mathrm{d} \phi_{c r 1}}{\mathrm{~d} \Psi_{p}}$. This implies that $\phi_{c r 1}$ declines more than $\phi_{c r 2}$. Therefore, an increase in $\Psi_{p}$ results in internal dispersion of the mobile factor.

\section{Conclusion}

The results of the current paper contribute to the existing literature showing that

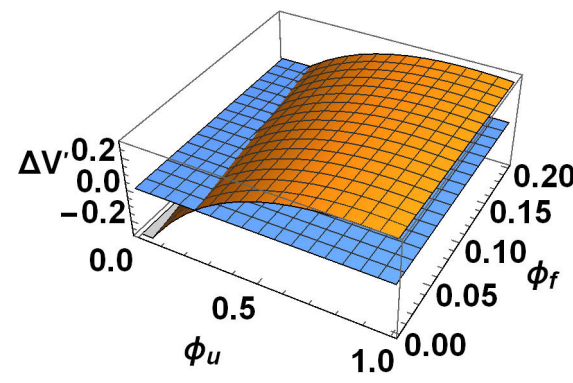

(a)Ethnocentrism

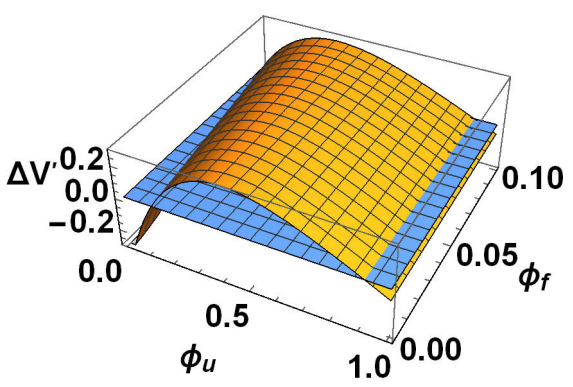

(b)Xenocentrism

Figure 4. Market equilibrium outcome: ethnocentrism vs xenocentrism. 
pro-agglomeration effects come from Foreign country being more important relative to Domestic country. I show that falling external trade barriers favor internal agglomeration. I clarify conceptually and analytically why this must be the case. Moreover, I find that the impact that comes from a decrease in relative productivity is identical to the one that comes from falling external trade barriers. More specifically, a reduction in relative productivity favors internal agglomeration of the mobile factor. Falling internal trade barriers also result in internal agglomeration; the same impact comes when the size of skilled workers located in Foreign country goes up. In addition, the model shows that a shift of consumer preferences in Domestic country with respect to goods that are made in Foreign country compensates for the trade barriers between Domestic country and Foreign country. This also results in internal agglomeration of the mobile factor. In Domestic country, a shift of consumer preferences in a region with respect to goods that are made in its partner region results 1) in internal agglomeration in the case of ethnocentrism, and 2) in internal dispersion in the case of xenocentrism. Also, an increase either in $\sigma$ or/and $\rho$ leads to internal dispersion of skilled workers within Domestic country. Finally, the welfare analysis suggests that, for some values of the internal freeness of trade, the market level of internal agglomeration is higher than the socially preferred level. For high and low values of the internal freeness of trade, both the market equilibrium allocation and the socially optimal allocation coincide with respect to the distribution of the mobile factor. This result complements the one that comes from a model consisting of two symmetric regions, which also shows that less agglomeration of the mobile factor is socially preferred for some values of the freeness of trade. Apart from the potential policy implications that come from the welfare analysis, the current paper illustrates some fundamental insights for the class of NEG models, in general. It, however, abstracts from differences in market structure. For example, as a further step, another model can be introduced where the home region produces an intermediate product, which is transported to the partner region, and then, it is exported as a final product. Such a model set up would make the differences in domestic and international transportation more realistic and interesting.

\section{Acknowledgements}

I am grateful to my supervisor Prof. Dr. Johannes Bröcker for his patience, advice, support and valuable comments.

\section{References}

[1] Fujita, M. and Krugman, P. (2004) The New Economic Geography: Past, Present and the Future. In: Florax, R.J.G.M. and Plane, D.A., Eds., Fifty Years of Regional Science. Advances in Spatial Science, Springer, Berlin, 139-164. https://doi.org/10.1007/978-3-662-07223-3_6

[2] Monfort, P. and Nicolini, R. (2000) Regional Convergence and International Integration. Journal of Urban Economics, 48, 286-306. 
https://doi.org/10.1006/juec.1999.2167

[3] Monfort, P. and van Ypersele, T. (2003) Integration, Regional Agglomeration and International Trade. CEPR Discussion Paper 3752. CEPR, London.

[4] Krugman, P. and Livas-Elizondo, R. (1996) Trade Police and Third World metropolis. Journal of Development Economics, 49, 137-150. https://doi.org/10.1016/0304-3878(95)00055-0

[5] Brülhart, M., Crozet, M. and Koenig, P. (2004) Enlargement and the EU Periphery: The Impact of Changing Market Potential. World Economy, 27, 853-875.

https://doi.org/10.1111/j.1467-9701.2004.00632.x

[6] Johnson, G.A. (2000) The Blackwell Dictionary of Sociology: A User's Guide to Sociological Language. 2nd Edition, Willey-Blackwell, Hoboken, NJ, 351.

[7] Balabanis, G., Mueller, R. and Melewar, T.C. (2002) The Relationship between Consumer Ethnocentrism and Human Values. Journal of Global Marketing, 15, 7-37. https://doi.org/10.1300/J042v15n03_02

[8] Klein, J.G. (2002) Us versus Them, or Us versus Everyone? Delineating Consumer Aversion to Foreign Goods. Journal of International Business Studies, 33, 345-363. https://doi.org/10.1057/palgrave.jibs.8491020

[9] Lindquist, J.D., Vida, I., Plank, R.E. and Fairhurst, A. (2001) The Modified CETSCALE: Validity Tests in the Czech Republic, Hungary, and Poland. International Business Review, 10, 505-516.

[10] Sharma, S., Shrimp, T.A. and Shin, J. (1995) Consumers Ethnocentrism: A Test of Antecedents and Moderators. Journal of the Academy of Marketing Science, 23, 26-37. https://doi.org/10.1007/BF02894609

[11] Ottaviano, G.I.P. and Thisse, J.-F. (2001) On Economic Geography in Economic Theory: Increasing Returns and Pecuniary Externalities. Journal of Economic Geography, 1, 153-179. https://doi.org/10.1093/jeg/1.2.153

[12] Tabuschi, T. and Thisse, J.-F. (2002) Taste Heterogeneity, Labor Mobility and Economic Geography. Journal of Development Economics, 69, 155-177.

https://doi.org/10.1016/S0304-3878(02)00057-3

[13] Charlot, C., Gaigne, C., Robert-Nicoud, F. and Thisse, J. (2006) Agglomeration and Welfare: The Core-Periphery Model in the Light of Bentham, Kaldor, and Rawls. Journal of Public Economics, 90, 325-347. https://doi.org/10.1016/j.jpubeco.2004.12.002

[14] Pflüger, M. and Südekum, J. (2008) Integration, Agglomeration and Welfare. Journal of Urban Economics, 63, 544-566. https://doi.org/10.1016/j.jue.2007.03.006

[15] Pflüger, M. (2004) A Simple, Analytically Solvable, Chamberlinian Agglomeration Model. Regional Science and Urban Economics, 34, 565-573. https://doi.org/10.1016/S0166-0462(03)00043-7

[16] Head, K. and Mayer, T. (2004) Market Potential and the Location of Japanese Investment in the European Union. The Review of Economics and Statistics, 86, 959-972. https://doi.org/10.1162/0034653043125257 